\title{
DETERMINING ELASTIC MODULUS OF THE MATERIAL BY MEASURING THE DEFLECTION OF THE BEAM LOADED IN BENDING
}

\author{
Jasmina Miljojković, Ivan Bijelić, Nenad Vranić, Nikola Radovanović, Milutin Živković
}

Preliminary communication

The paper presents a theoretical model and design solution for the device which determines the modulus of elasticity by bending the material (test samples), instead of the usual stretching. The device was designed, assembled and successfully tested in the laboratory. Experimental determination of the elastic modulus was conducted by measuring the deflection of samples under a constant load. Values of the elastic modulus resulted from theoretical relations. Measurement was performed and measurement errors, i.e. device errors, were analysed.

Keywords: deflection; device for determining the modulus of elasticity; elastic modulus; stress

Određivanje modula elastičnosti materijala mjerenjem progiba grede opterećene na savijanje

Prethodno priopćenje

U radu je dan teorijski model i projektno rješenje uređaja za određivanje modula elastičnosti na osnovi savijanja, a ne istezanja materijala (ispitnih uzoraka) kao što je uobičajeno. Uređaj je projektiran, realiziran i uspješno testiran u laboratoriju. Provedeno je eksperimentaln o određivanje modula elastičnosti mjerenjem vrijednosti progiba ispitivanih uzoraka materijala pri konstantnom opterećenju. Na bazi teorijskih ovisnosti, dolazi se do vrijednosti modula elastičnosti. Provedeno je mjerenje i analizirane su greške mjerenja, odnosno uređaja.

Ključneriječi: modul elastičnosti; naprezanje; progib; uređaj za određivanje modula elastičnosti

\section{Introduction}

Young's modulus of elasticity is a characteristic of material which is not dependant on the stress or on the relative deformation. There are several methods for determining the modulus of elasticity. The most known methods are: mechanical (static and dynamic), acoustic, ultrasonic, resonant, optic, etc. $[1 \div 4]$. Mechanical methods are the most compatible for determining the elastic modulus of thin materials such as rods, wires, fibres.

Motra et al. [5] performed an assessment of strain measurement techniques to characterize mechanical properties of structural steel. Sixty samples were cut from the S 235 web of the I-profile in longitudinal and transverse directions in four different dimensions. 3D scanner and vernier calliper were used to analyse the geometry of samples, while the strain values were determined by using a strain gauge, extensometer and machine crosshead motion. Motra et al. quantitatively compared the results of three different techniques of strain measurement. Comparison was based on the calculation of mechanical properties (modulus of elasticity, yield strength, tensile strength, percentage elongation at maximum force) of structural steel.

Mirambelland Real [6] studied the flexural behaviour of stainless steel beams and to calculate the maximum deflection for different load levels, especially near service conditions. The cross-sections of the beams were square, and rectangular hollow sections, and H-sections. The simply supported beams were subjected to a concentrated load at mid-span and the continuous beams to two concentrated loads at close to the mid-span. Deflections obtained considering the variation of the modulus of elasticity along the length of the element and the possible redistribution of internal forces due to material nonlinearity effects are very close to the experimental deflection value.
Oliver and Pharr [7] improved in 2011 their method for measuring hardness and elastic modulus by instrumented indentation techniques, originally introduced in 1992. This model was developed to measure the hardness and elastic modulus of a material from indentation load-displacement data obtained during one cycle of loading and unloading and has been used in the characterization of small-scale mechanical behavior.

Kvetan et al. [8] presented an accurate measurement of elastic modulus of thin quick-vibrating wire samples by Searle's pendulum. The paper provides detailed statistical analysis of measurement of less used samples - with a rectangular cross-section. Vibrations were registered and analysed by electronic sensor or camera. High accuracy of Young's modulus measurement was provided by exclusively using the instruments on electronic basis, including micrometer, calliper and weight.

Ohtsuki [9] defined a new measuring method of Young's modulus for flexible materials, based on a large bending deformation of specimen subjected to axial compressive forces at both fixed ends. This method eliminates the undesirable effects of loading nose, which are common in conventional three- or four-point bending. Two kinds of flexible materials (PVC: a high-polymer thin plate, SWPA: a piano wire) were tested and results showed that this method is suitable for flexible materials such as thin long fibre materials (glass fibre, carbon fibre, optical fibre, etc.) or thin sheet materials.

Tohmyoh et al. [10] reported a mechanical testing methodology for thin wires based on small-scale bending under lateral load. For the sample arrangement, the thin wires were cut and welded by Joule heating. A small-span bending load was applied at the local area of the wire with two opposite probes, and the small force acting on the loading tip was measured with a capacitance sensor.

From the load-displacement relationships obtained via experiments, Ficker [11] describes an extended measurement of Young's modulus of elasticity 
containing, besides the traditional mechanical experiment, a less frequent gauge measurement. Ficker points out that if highly accurate measurements are not required, sophisticated electronic devices (often used in special laboratories performing stress analysis) can be replaced by a common digital micro voltmeter with large input resistance. Thus, it is possible to simultaneously perform electrical and mechanical measurements, using one common sample and enabling comparison between two independent experimental methods.

Pacheco and Pina [12] calculated and drew the form of an elastic rod in equilibrium subject to a buckling by the action of two opposite forces at its ends. The full expression for the radius of curvature in the equation of the beam is considered. The differential equation describing the form of the rod, written in terms of the arc length and the angle that forms the tangent line to the curve with the horizontal axis of coordinates, is exactly the same one finds in describing the dynamics of great amplitude oscillations of a simple pendulum. This equation is solved exactly in terms of Jacobi's elliptic functions. The solutions are drawn by using in iterated form the addition formulas of those functions. Bowden [13] considers possible deviations of stretched wire from the simple 2-dimensional catenary form. Tobushi et al. [14] conducted experiments to investigate the deformation behaviours and fatigue properties of a superelastic thin tube (SE-tube) and a high-elastic thin wire (HE-wire) of TiNi alloy under conditions of pulsating-plane, alternating-plane and rotating bending. Antherieu et al. [15] proposed and developed a new principle using two universal joints to enable pure bending conditions. This principle was applied to design an apparatus suitable for testing the small-size samples (such as wires of diameter $<1 \mathrm{~mm})$ at small curvature radii $(\cong 5 \mathrm{~mm})$ and to specifically provide small size samples moment-curvature relationship. This article underlines and validates the abilities of this new apparatus by performing and analysing tests on samples made of well-known material. Misseroni et al. [16] defined a model for teaching elastic frames. The model consists of a two-story, one-bay planar frame, which can be deformed by applying a concentrated force at different positions. This force is measured and transmitted to a computer, which calculates the structure's deformation through linear elastic analysis in real time and displays its deformed shape on monitor.

This paper presents a theoretical model and design solution for the device that determines the modulus of elasticity by bending the material (test samples), instead of the usual stretching [17]. The measurement of the elastic modulus was performed and measurement errors, i.e. the device errors, were analysed.

\section{Mechanical model of the device}

Let us assume that a rod (a sample of the analysed material) is placed on two supports, as shown in Fig. 1a, with a force $F$ acting at its midpoint and directed vertically downwards. Under the effect of this force, the rod bends (see Fig. 1b). Before and after the deformation, the situation in all vertical cross sections of the rod parallel to its length remains the same; thus, the complete picture of "events" undergoing within the rod becomes "projected" on the plane of the drawing. Horizontal lines parallel to the length of the rod are curved. All these lines change their length, except for the lines at the plane of symmetry, which only curve, without changing their length. These lines form the neutral surface and on the drawing they are all projected on the line NN', i.e. neutral line. Finally, lines parallel to the height of the rod do not change their length, but they change their direction whilst remaining normal to the (curved) neutral line.

a)

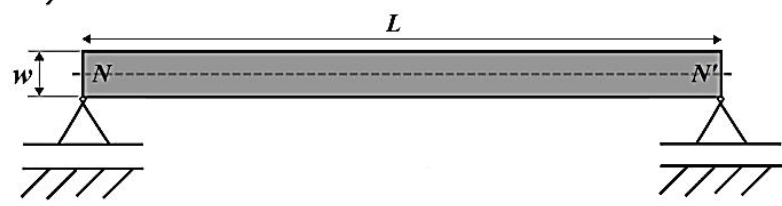

b)

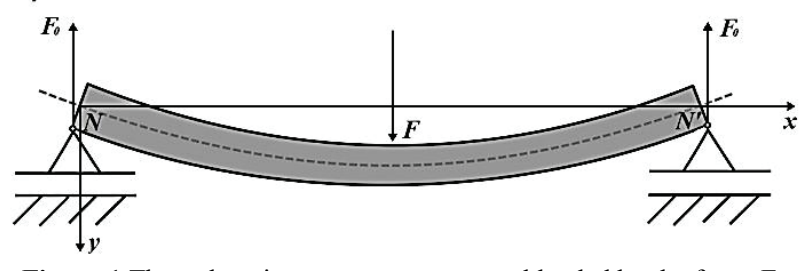

Figure 1 The rod resting on two supports and loaded by the force $F$

Let us assume that the rod is only laid on the supports. At the contact point between the rod and (every) support, some stress distribution appears, which can be replaced by the resultant force (with which the support affects the rod) and the resultant couple of forces. As the system is symmetric, it can be concluded that the resultant forces at the supports must be equal, while the couples are opposite. As the rod is in balance, the sum of all external forces acting on it remains zero, thus the force in supports $\vec{F}_{0}$ must be:

$\vec{F}_{0}=-\frac{\vec{F}}{2}$

whereas $\vec{F}$ is the force which loads the rod at the midpoint, between the supports. Apart from it, as the rod rests on supports only from topside, there are no conditions for the appearance of the resultant couple of forces on either of the supports.

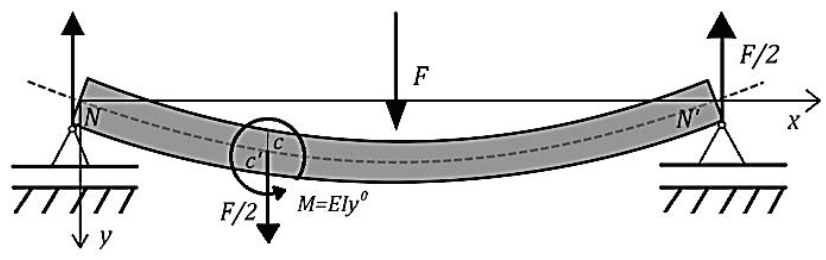

Figure 2 Part of the rod after bending

Let us observe the cross section $\mathrm{CC}^{\prime}$ closer to the left support, Fig. 2. Let us then observe the part of the rod between the left support and the cross section $\mathrm{CC}^{\prime}$. This part is in equilibrium, thus the total effect of external force and total moment of external forces on it must be equal to zero. On the left end of the observed part of the rod, external forces appear as the result of the interaction 
with the support, and, as we stated, provide a total force of $F / 2$ directed upwards and zero force couple. The right end of the observed part of the rod is affected by the remainder of the rod, by elastic forces and these forces are, for the observed part of the rod, external.

It is clear that the total elastic force at the observed right end of the rod will be equal to $F / 2$ and that it will be directed downwards, which indicates that in the plane of the cross section, tangential forces of shear will appear, and that they will be directed downwards. Analysis of these forces is, at the moment, not of significance to us, apart from the fact that they, together with the forces on the support, form a couple $F_{x} / 2$, whereas $x$ is the distance of plane $\mathrm{CC}^{\prime}$ from the support; this couple tends to turn the observed part of the rod in the clockwise direction. What mattered here was that the elastic forces on the right end of the rod form a couple of forces:

$M_{\mathrm{e}}=E \cdot I \cdot y^{\prime \prime}$

which balances the stated couple $F_{x} / 2$ and tends to rotate the rod in the counter-clockwise direction (as the upper parts of the rod are compressed and lower ones elongated), which leads us to:

$$
E I y^{\prime \prime}=-\frac{F_{x}}{2}
$$

respecting that:

$$
y^{\prime \prime}=\frac{\mathrm{d}^{2} y}{\mathrm{~d} x}
$$

By integrating this equation by $x$ we find:

$$
y^{\prime}(x)=-\frac{F_{x}}{4 \cdot E \cdot I}+y_{0}^{\prime}
$$

whereas:

$$
\begin{aligned}
& y^{\prime}=\frac{\mathrm{d} y}{\mathrm{~d} x} \\
& y_{0}^{\prime}=\left(\frac{\mathrm{d} y}{\mathrm{~d} x}\right)_{x=0}
\end{aligned}
$$

whereas $y_{0}^{\prime}$ is the first derivative at the point $x=0$. This derivative is unknown, but it is known that, due to the symmetry of the problem, the first derivative must be equal to zero at the point $x=L / 2$, from which we deduce that:

$$
y_{0}^{\prime}=\frac{F \cdot L^{2}}{16 \cdot E \cdot I}
$$

That is:

$$
y^{\prime}(x)=\frac{F}{4 \cdot E \cdot I}\left(\frac{L^{2}}{4}-x^{2}\right)
$$

By integrating the $y^{\prime}(x)$ by $x$ we find that:

$$
y(x)=\frac{F}{4 \cdot E \cdot I}\left(\frac{L^{2}}{4} \cdot x-\frac{x^{3}}{3}\right)+y_{0}
$$

whereas $y_{0}$ is the bending of the rod at the left support, that is, for the $x=0$. This bending is $y_{0}=0$, which allows us to find the bending profile:

$$
y(x)=\frac{F_{x}}{48 \cdot E \cdot I}\left(3 \cdot L^{2}-4 \cdot x^{2}\right)
$$

Therefore, the deflection $f$, that is, the bending of the rod at its midpoint, where $x=\frac{L}{2}$, becomes:

$$
f=\frac{F \cdot L^{3}}{48 \cdot E \cdot I}
$$

whereas: $f$-deflection, $F$ - bending force, $L$ - distance between supports, $E$ - elastic modulus and $I-$ momentum of inertia.

From the equation for calculating the deflection, we can conclude that the elasticity module is:

$$
E=\frac{F \cdot L^{3}}{48 \cdot E \cdot f}
$$

This formula applies to the field of elastic deformations which can be defined by condition:

$\sigma=\frac{M_{\mathrm{f}}}{W} \leq \sigma_{\mathrm{e}}$

whereas: $\sigma$ - stress, $W-$ resistance momentum of the cross section area, $\sigma_{\mathrm{e}}-$ elasticity limit.

\section{Device design solution}

Fig. 3 shows a model of the device for the elastic modulus testing.

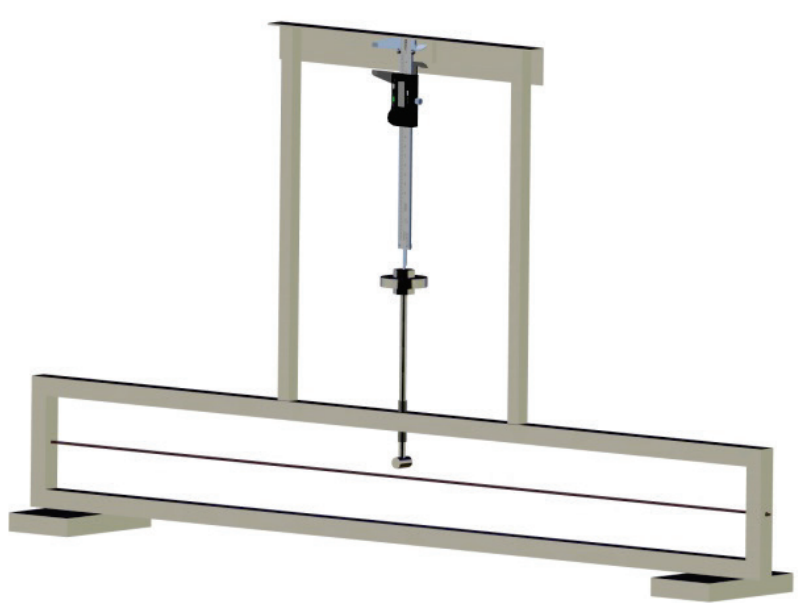

Figure $3 \mathrm{CAD}$ model of the device for analysis of the elastic modulus 
The bearing construction of this device is made of aluminium and structural steel. Device dimensions are $1000 \times 500 \times 100 \mathrm{~mm}$, while the mass of the device $<5$ $\mathrm{kg}$. The device cannot be disassembled. The diameter of the testing samples is $3 \mathrm{~mm}$, and its length $1000 \mathrm{~mm}$. Deflection is measured with a digital calliper, with the measurement range of $0 \div 150 \mathrm{~mm}$ and with the accuracy of $0,01 \mathrm{~mm}$.

The basic elements of the equipment are the measurement device (digital calliper) and the weight which affects the analysed sample via the cylinder of $5 \mathrm{~mm}$ diameter. Contact between the weight and the sampled material which is analysed is at one point, that is, the load is concentrated, while the analysed material rests on supports whose distance from each other equals 960 $\mathrm{mm}$. The weight is positioned at the midpoint of the distance between two supports.

Initially, the weight makes contact with the analysed sample, that is, the contact is made without the transfer of the weight on the sample, which is achieved by using a shim (Fig. 4). After the placement of the test sample and the shim, a screw is fastened at the back side of the device, which will prevent the movement of the weight, that is, secure it in its initial, zero position (Fig. 5a). Position of the weight is then defined by using the calliper. When the top of the calliper makes contact with the weight guide, device "resets" and that position is assumed as initial, referent point (Fig. 5a). The mass of the weight has been previously measured and equals $152,018 \mathrm{~g}$.

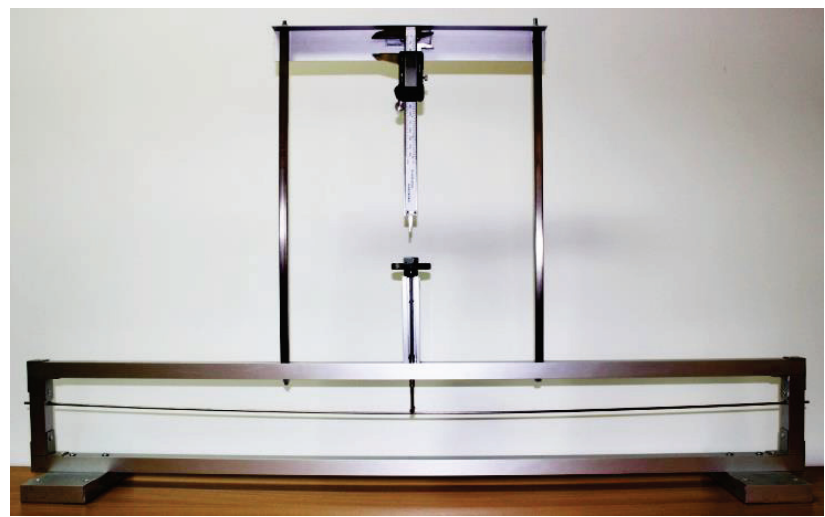

Figure 4 Initial position with a shim

By unfastening the screw from the back side of the device, the weight starts to move and bending of the sampled material commences. Attention is paid not to allow rapid movements of weight or impacts. After stabilization, the weight position is secured via the screw at the back side of the device (Fig. 5b.)

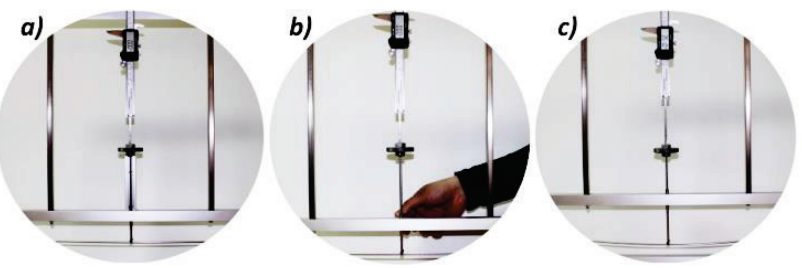

Figure 5 a) resetting the device b) manipulation of the screw c) measurement of the deflection.

After fixating, the position of the weight by moving the calliper to the point of contact with the weight guide, the value of the deflection under the given load is determined (Fig. 5c). Elastic modulus is quite easy to calculate based on the measured value of the deflection, known design characteristics of the device (distance between the supports) and known dimensions of the material which is analyzed (diameter of the test sample).

\section{Elastic modulus measurement results and analysis of the measurement errors \\ 4.1 Elastic modulus measurement results}

Elastic modulus value is calculated using the Eq. (13), which is derived from the Eq. (12) for determining the deflection of the beam, laid on two supports with symmetrically concentrated load.

The designed and constructed device was used to conduct a measurement of the elastic modulus of test samples made of chromed, fireproof steel X5CrNi18-10.

The device was tested, and the results of 12 measurements are shown in Tab. 1.

Table 1 Measurement results

\begin{tabular}{|c|c|}
\hline Number of experiment & Elastic modulus $E, \mathrm{MPa}$ \\
\hline 1 & 200732,685 \\
\hline 2 & 192730,239 \\
\hline 3 & 199746,711 \\
\hline 4 & 192515,558 \\
\hline 5 & 195068,670 \\
\hline 6 & 195565,309 \\
\hline 7 & 195897,809 \\
\hline 8 & 195731,418 \\
\hline 9 & 196846,062 \\
\hline 10 & 192891,565 \\
\hline 11 & 204231,423 \\
\hline 12 & 194848,751 \\
\hline Average value of the elastic modulus & 196400,517 \\
\hline Dispersion & 3390,461 \\
\hline & \\
\hline &
\end{tabular}

Each of the 12 conducted experiments (Tab. 1) was performed by different operators, while each experiment was comprised of 30 measurements. Initial data for one of the performed measurements were:

Distance between supports: $L=960 \mathrm{~mm}$

Test sample diameter: $d=3 \mathrm{~mm}$

Weight mass: $m=0,152 \mathrm{~kg}$

Deflection: $f=35,01 \mathrm{~mm}$

$\sigma_{\mathrm{e}}=190 \mathrm{MPa}-$ elastic limit of high-alloyed stainless steel X5CrNi18-10 which was discussed in this paper.

Based on the previously stated data, the bending force can be calculated via:

$$
F=m \cdot g=1,491 \mathrm{~N}
$$

Momentum of inertia for the circular cross section is equal to:

$I=\frac{d^{4} \cdot \pi}{64}=3,976 \mathrm{~mm}^{4}$

From the Eq. (13) for the calculation of the deflection, it follows that the elastic modulus is equal to: 


$$
E=\frac{F \cdot L^{3}}{48 \cdot E \cdot f}=197520,9 \mathrm{MPa}
$$

Verification of the maximal achieved stress is done by the formula:

$$
\begin{aligned}
& \sigma=\frac{M_{\mathrm{f}}}{W}=\frac{\frac{F}{2} \cdot \frac{L}{2}}{\frac{d^{3} \cdot \pi}{16}}=\frac{16 \cdot F \cdot L}{4 \cdot d^{3} \cdot \pi}=\frac{4 \cdot 1,491 \cdot 960}{d^{3} \cdot \pi} \\
& \sigma=67,512 \mathrm{MPa}
\end{aligned}
$$

Based on the characteristics of the material, it can be concluded that the maximal stress is lower than the allowed stress, that is:

$\sigma=\frac{M_{\mathrm{f}}}{W} \leq \sigma_{\mathrm{e}} \Rightarrow 67,512 \mathrm{MPa}<190 \mathrm{MPa}$

The obtained average value of the elastic modulus (Tab. 1) is very close to the theoretical value for the analysed material. The difference between obtained and theoretical value (according to the ASTM standards) is equal to just $1,239 \%$.

\subsection{Analysis of the measurement errors}

Starting from the Eqs. (13) and (16) the elastic modulus can be expressed as:

$$
E=\frac{64 \cdot F \cdot L^{3}}{48 \cdot \pi \cdot d^{4} \cdot f}
$$

From the previous equation it can be concluded that the elastic modulus represents the function of the force, length, diameter and deflection.

$$
E=\Phi(F, L, d, f)
$$

Based on the expanded Gauss equation, the measurement error can be calculated:

$$
W_{E}=\sqrt{\left[\left(\frac{\partial \Phi}{\partial F}\right)^{2} \cdot W_{F}^{2}+\left(\frac{\partial \Phi}{\partial L}\right)^{2} \cdot W_{l}^{2}+\left(\frac{\partial \Phi}{\partial d}\right)^{2} \cdot W_{d}^{2}+\left(\frac{\partial \Phi}{\partial f}\right)^{2} \cdot W_{f}^{2}\right]}
$$

whereas: $W_{F}$ - error in force, $W_{l}-$ error in length, $W_{d}-$ error in diameter, $W_{f}$ - error in deflection.

In Fig. 6, the cross section of the device is shown, while Figs. 7, 8 and 9, show the details, characteristic from the aspect of the source of measurement errors.

Let us observe Fig. 7, which shows the effect of the angle on the value of the realized force. In the ideal case, when $\alpha=0$, force $F$ equals:

$$
F_{i}=m \cdot g
$$

In the case of turning $(\alpha>0)$, when the system is not levelled, we have:

$$
F_{\mathrm{st}}=m \cdot g \cdot \cos \alpha-F_{\mathrm{t}}=m \cdot g \cdot \cos \alpha-F_{\mathrm{N}} \cdot \mu
$$

that is:

$$
\begin{aligned}
& F_{\text {st }}=m \cdot g \cdot \cos \alpha-m \cdot g \cdot \sin \alpha \cdot \mu \\
& F_{\text {st }}=m \cdot g \cdot(\cos \alpha-\mu \cdot \sin \alpha)
\end{aligned}
$$

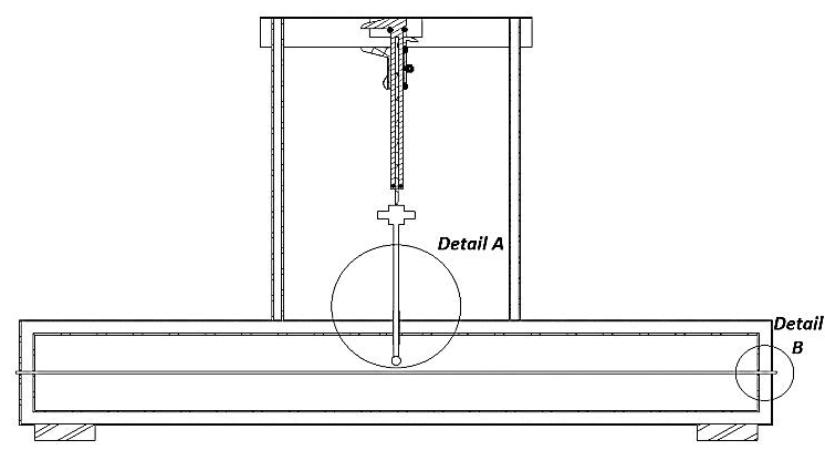

Figure 6 Cross section of the educational device

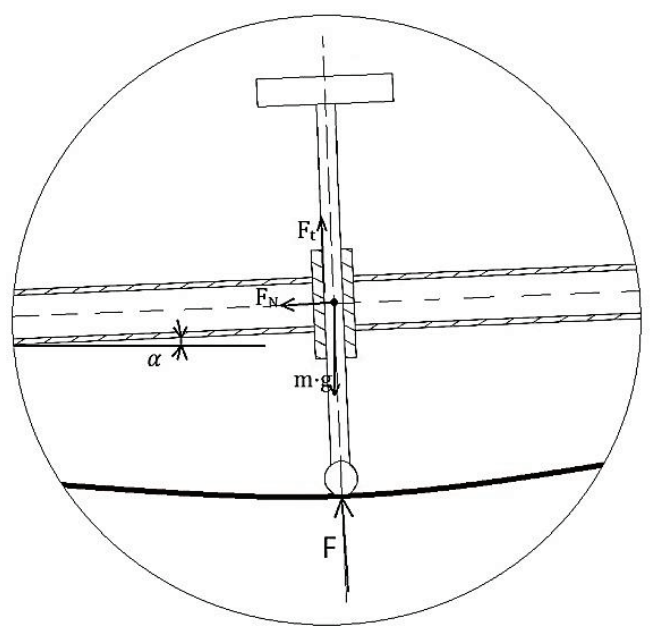

Figure 7 Detail A: The effect of the error in the levelling angle on the value of the realized force

In order to disregard the effect of the friction force component, levelling of the device must be performed. Levelling should not be performed at the supports, but in the area of the rod, between the weight and the gap, as shown in Fig. 8. With the assistance of the level for tool specialists, we place the rod under the angle of $90^{\circ}$.

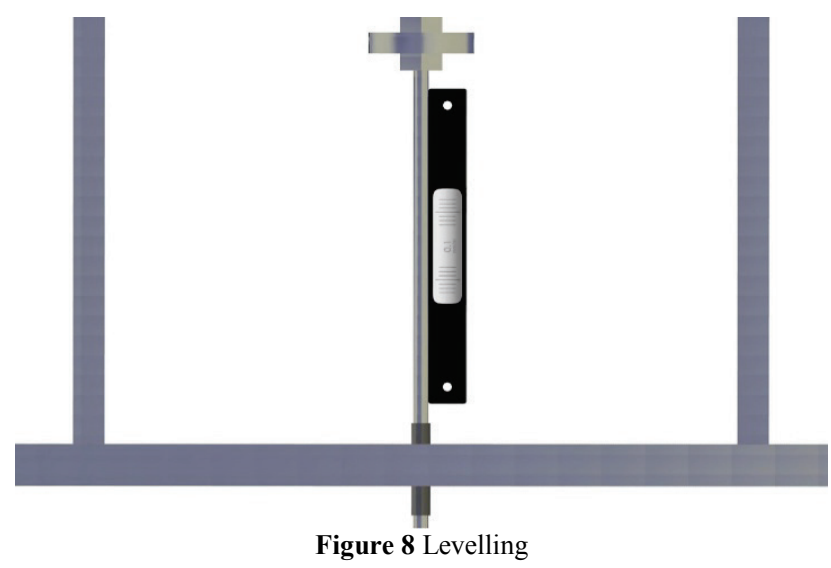

The analysis is as follows:

Mass of the weight: $m=0,152 \mathrm{~kg}$

$F_{i}=m \cdot g=1,491 \mathrm{~N}$ 


$$
\begin{aligned}
& F_{\mathrm{st}}=m \cdot g \cdot(\cos \alpha-\mu \cdot \sin \alpha)= \\
& =1,491 \cdot(\cos 0,5-0,1 \cdot \sin 0,5)=1,490 \mathrm{~N} \\
& W_{F}=F_{i}-F_{\mathrm{st}}=1,491-1,490=0,001 \mathrm{~N} \\
& \frac{\partial \Phi}{\partial F}=\frac{\partial\left(\frac{64 \cdot L^{3} \cdot F}{48 \cdot \pi \cdot d^{4} \cdot f}\right)}{\partial F}=\frac{64 \cdot L^{3}}{48 \cdot \pi \cdot d^{4} \cdot f} \\
& \frac{\partial \Phi}{\partial F}=\frac{64 \cdot 960^{3}}{48 \cdot \pi \cdot 3^{4} \cdot 35}=132449,207
\end{aligned}
$$

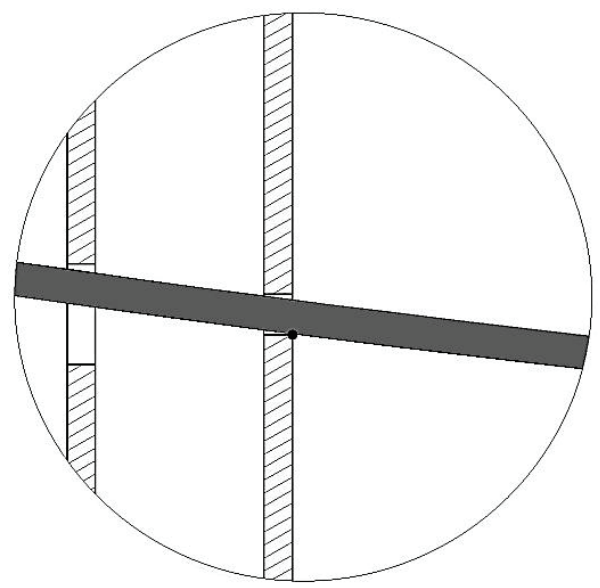

Figure 9 Detail B: Contact of the edge of the gap with the wire

Based on Fig. 9 we notice that the contact is made at the point on the supports. Because the contact was made at the point, we have a pure bending, without sliding. The stress is the highest at this point, and it is grouped on the estimated width of $0,1 \mathrm{~mm}$.

In terms of construction, high distance between the supports has been chosen in order to reduce the relative error. The error caused by the distance length equals:

$$
\begin{aligned}
& \frac{\partial \Phi}{\partial L}=\frac{\partial\left(\frac{64 \cdot L^{3} \cdot F}{48 \cdot \pi \cdot d^{4} \cdot f}\right)}{\partial L}=\frac{64 \cdot 3 \cdot L^{3} \cdot F}{48 \cdot \pi \cdot d^{4} \cdot f} \\
& \frac{\partial \Phi}{\partial F}==\frac{64 \cdot 3 \cdot 960^{3} \cdot 1,491}{48 \cdot \pi \cdot 3^{4} \cdot 35}=617,253
\end{aligned}
$$

whereas: $W_{l}=0,1 \mathrm{~mm}$.

Error based on the test sample diameter (which affects the value of the momentum of the inertia) equals: $W_{d}=0,02 \mathrm{~mm}$.

$$
\begin{aligned}
& \frac{\partial \Phi}{\partial d}=\frac{\partial\left(\frac{64 \cdot L^{3} \cdot F}{48 \cdot \pi \cdot d^{4} \cdot f}\right)}{\partial d}=-\frac{256 \cdot L^{3} \cdot F}{48 \cdot \pi \cdot d^{5} \cdot f} \\
& \frac{\partial \Phi}{\partial d}=-\frac{256 \cdot 960^{3} \cdot 1,491}{48 \cdot \pi \cdot 3^{5} \cdot 35}=-263361,121
\end{aligned}
$$

whereas: $W_{d}=0,02 \mathrm{~mm}$.

The error in the measurement of deflection is related to the error of the calliper. The calliper has a measurement range from 0 to $150 \mathrm{~mm}$ with a margin of error equal to $0,01 \mathrm{~mm}$, which leads to: $W_{f}=0,01 \mathrm{~mm}$.

$$
\begin{aligned}
& \frac{\partial \Phi}{\partial f}=\frac{\partial\left(\frac{64 \cdot L^{3} \cdot F}{48 \cdot \pi \cdot d^{4} \cdot f}\right)}{\partial f}=-\frac{64 \cdot L^{3} \cdot F}{48 \cdot \pi \cdot d^{4} \cdot f^{2}} \\
& \frac{\partial \Phi}{\partial f}=-\frac{256 \cdot 960^{3} \cdot 1,491}{48 \cdot \pi \cdot 3^{4} \cdot 35^{2}}=-5643,451
\end{aligned}
$$

Finally, total error during the calculation of the elastic modulus is equal to:

$$
\begin{aligned}
& W_{E}=\sqrt{132449,207^{2} \cdot 0,001^{2}+617,253^{2} \cdot 0,1^{2}+} \\
& +(-263361,121)^{2} \cdot 0,02^{2}+(-5643,451)^{2} \cdot 0,01^{2} \\
& W_{E}=5271,863, \text { respectively } 2,669 \% .
\end{aligned}
$$

\section{Discussion}

Classical methods for determining the elastic modulus, known in the literature, are based on the acquiring of the elastic modulus value by using the Hook's diagram and observing the elongation of the sampled material using extensometer. Those processes are far more complicated and lead to larger errors.

In the case of the device we are discussing, the elastic curve of the beam is used for observing the theoretical dependence of the deflection as the function of the constant load, constant momentum of inertia and constant distance between supports, and thus the elastic modulus is determined. The advantage of this method is represented in the achieved accuracy in measurement of $0,01 \mathrm{~mm}$, when the measured deflection $f$ is $35 \mathrm{~mm}$. The distance between supports of $960 \mathrm{~mm}$ enabled the measurement of the high values of deflection. This value has been measured on the coordinate measurement machine, where the projected deviation due to the shift in the resulting resistance of supports equals $0,1 \mathrm{~mm}$.

The concept of the device enables us to disregard the effect of the friction, by levelling the supports and levelling the axis of the load. The force of load is accomplished via the weight measured on the precise analytical scale with the accuracy of $0,0001 \mathrm{~kg}$.

Measurement results indicate that the error in the measurement is only $1,239 \%$, taking into consideration the value defined by ASTM standard for the analysed material X5CrNi18-10. Measurement errors of 2,669\% were calculated by using the Eq. (22) which is based on the known Gauss law of the error distribution. Testing results are compatible to the estimated error which equals $W_{E}=5271,863=2,669 \%$. As it can be seen, the error estimated according to the Eq. (22) is larger than the error occurred during the testing of the device, which is, from the aspect of probability theory and mathematical statics, absolutely correct.

Construction of the device is simple and low cost. According to the opinion of the authors of this study, the device can be efficiently used for determining the elasticity modules of different types of metal and nonmetal materials, and especially for the educational purposes. 


\section{Conclusion}

Based on theoretical analysis and experimental research we can come to the following conclusions:

- The presented method provides precise measurement of the elastic modulus. Measurement errors are, in relation to ASTM and ISO standards, at around two percent, so it can be assumed that the value of the elastic modulus measured on the designed device remains adequate to the theoretical value of the elastic modulus for the analysed material.

- The procedure for determining the elastic modulus is quite simple - based on theoretical dependence, by free lowering of the weight without an additional energy source we determine the elasticity module.

- In terms of construction, large distance between the supports was chosen in order to gain higher values of deflection and the lowest possible relative error.

- By vertical movement of the load downwards and by proper levelling we provide the pre-conditions which allow us to ignore the friction in the guide of the weight carrier.

- Based on the measured stress it can be noticed that the elasticity limit is far lower than the theoretical stress limit for the examined material, which provides the condition for keeping the deformation field in the area of elasticity.

- Measurement results and error analysis indicate that the obtained values are in the close range of its theoretical values.

- Possible error which an operator could make due to the inexpert handling of the device is reduced to minimum, as the two most important parameters, the distance between supports and the diameter of the sampled material, are measured by precise measuring instrumentation, leaving the operator to simply read the value from the display of the digital calliper.

- The results of the device testing are compatible with the estimated probable error, which is absolutely correct from the aspect of the probability theory and mathematical statistics.

- According to the opinion of the authors the device discussed in this paper is quite appropriate for educational purposes.

Authors of this paper consider that further research should go in the direction of the development of the device for determining the shear modulus of various materials. Shear modulus can be determined by measuring the angle of torsion of the slender rod, at the known values of the momentum of torsion, torsion length and the size of the cross section of the rod, that is, its inertia momentum. In the elasticity theory, it is known that Poisson's ratio, as one of the basic characteristics of the material, can be determined properly via theoretical dependencies between the elasticity module and the shear modulus. The development of the device for sheer modulus determination, in principle, does not require extensive investments, or dealing with significant obstacles of technical nature. Especially, bearing in mind that, at the small torsion momentums of the slender rod, low value of its cross section and high torsion length, when working with metal materials, very high values of the torsion angle can be achieved, which then minimizes the relative measurement error.

\section{References}

[1] Radovic, E.; Lara-Curzio, E.; Riester, L. Comparison of different experimental techniques for determination of elastic properties of solids. // Materials Science and Engineering: A. 368, 1-2(2004), pp. 56-70. https://doi.org/10.1016/j.msea.2003.09.080

[2] Bamber, M. J.; Cooke, K. E.; Mann, A. B.; Derby, B. Accurate determination of Young's modulus and Poisson's ratio of thin films by a combination of acoustic microscopy and nanoindentation. // Thin Solid Films. 398-399(2001), pp. 299-305. https://doi.org/10.1016/S0040-6090(01)01341-4

[3] Rho, J. Y.; Ashman, R. B.; Charles, H. T. Young's modulus of trabecular and cortical bone material: Ultrasonic and microtensile measurements. // Journal of Biomechanics. 26, 2(1993), pp. 111-119. https://doi.org/10.1016/0021-9290(93)90042-D

[4] Kiesewetter, L.; Zhang, J-M. Determination of Young's moduli of micromechanical thin films using the resonance method. // Sensors and Actuators A: Physical. 35, 2(1992), pp. 153-159. https://doi.org/10.1016/0924-4247(92)80154-U

[5] Motra, H. B.; Hildebrand, J.; Dimmig-Osburg, A. Assessment of strain measurement techniques to characterise mechanical properties of structural steel. // Engineering Science and Technology, an International Journal. 17, 4(2014), pp. 260-269. https://doi.org/10.1016/j.jestch.2014.07.006

[6] Mirambell, E.; Real, E. On the calculation of deflections in structural stainless steel beams: an experimental and numerical investigation. // Journal of Constructional Steel Research. 54, 1(2000), pp. 109-133. https://doi.org/10.1016/S0143-974X(99)00051-6

[7] Oliver, W. C.; Pharr, G. M. Measurement of hardness and elastic modulus by instrumented indentation: Advances in understanding and refinements to methodology. // Journal of Materials Research. 19, 1(2004), pp. 3-20. https://doi.org/10.1557/jmr.2004.19.1.3

[8] Kvetan, K.; Bučány, M.; Bošák, O.; Kubliha, M.; Kotianová, J. Measuring of Young's modulus of thin samples using the quick bending vibrations of Searle's pendulum. // ActaMechatronica - International Scientific Journal about Mechatronics. 1, 2(2016), pp. 1-5.

[9] Ohtsuki A. A new measuring method of Young's modulus for flexible materials. // SEM annual conference and exposition on experimental and applied mechanics, Proceedings of the 2005 SEM annual conference / Portland, 2005, pp. 113(1)-113(8).

[10] Tohmyoh, H.; Akanda, M. A. S.; Takeda, H.; Saka M. Determination of elastic-plastic properties of metallic thin wires by small-span bending test. // Glass, Inverse Problems, History of Fracture MechanicsAnd Fatigue, Ice Mechanics and IceStructures Interaction, Proceedings of the ICF12, Ottawa, 2009, pp. 1-6.

[11] Ficker, T. Young's modulus of elasticity in student laboratories. // Physics Education. 34, 6(1999), pp. 376. https://doi.org/10.1088/0031-9120/34/6/407

[12] Pacheco Q. M. E.; Pina, E. The elastic rod. //Revista Mexicana de Fi'sica E. 53, 2(2007), pp. 186-190.

[13] Bowden, G. Stretched wire mechanics. // 8th International Workshop on Accelerator Alignment, Proceedings of the IWAA2004, Geneva, 2004, pp. 1-9.

[14] Tobushi, H.; Furuichi, Y.; Sakuragi, T.; Sugimoto, Y. Bending fatigue properties of a superelastic thin tube and a high-elastic thin wire of TiNialloy. // Materials Transactions. 50, 8(2009), pp. 2043-2049. https://doi.org/10.2320/matertrans.M2009073 
[15] Antherieu, G.; Connesson, N.; Favier, D.; Mozer, P.; Payan, Y. Principle and experimental validation of a new apparatus allowing large deformation in pure bending: Application to thin wire. // Experimental Mechanics. 56, 3(2016), pp. 475482. https://doi.org/10.1007/s11340-015-0102-5

[16] Misseroni, D.; Bigoni, D.; Dal Corso, F. A model for teaching elastic frames. // Journal of Materials Education. 36, 5-6(2014), pp. 169-174.

[17] Lord, J. D.; Morrell,R.M. Elastic modulus measurement obtaining reliable data from the tensile test. // Metrologia. 47, 2(2010), pp. 41-49.

https://doi.org/10.1088/0026-1394/47/2/S05

\section{Authors' addresses}

Jasmina Miljojković, MSc.

Faculty of Engineering University of Kragujevac,

Sestre Janjić 6, 34000 Kragujevac, Srbija

E-mail: jasmina.miljojkovic@mfkg.rs

Ivan Bijelić, MSc.

Polytechnic College "Novi Beograd",

Bulevar Zorana Đinđića 152a, 11070 Novi Beograd, Srbija

E-mail: ivan.bijelic@visokatehnicka.edu.rs

Nenad Vranić

Faculty of Engineering University of Kragujevac,

Sestre Janjić 6, 34000 Kragujevac, Srbija

E-mail: nenadvranic993@gmail.com

\section{Nikola Radovanovic}

Faculty of Engineering University of Kragujevac,

Sestre Janjić 6, 34000 Kragujevac, Srbija

E-mail: nikolar93@gmail.com

\section{Milutin Živković, PhD}

Technical College of Applied Studies in Mechanical Engineering Radoja Krstića 19, 37240 Trstenik, Srbija

E-mail: milutinzivkovicts@gmail.com 